interpreting symptoms than have ever been caused by failure to hear a murmur, feel a mass, or take an electrocardiogram." How greatly needed is this dictum in these days when the patient tends to be submitted to a system of specialist examinations (and sometimes treatments) from a hurried haphazard examination. And in these days of economic stress, once labelled, the patient is often willing or even asking to have it so, for quite minor complaints. As other examples take the following didactic statements in italics:"The presence of normal heart sounds does not necessarily indicate a normal heart; a seriously diseased heart may sound perfectly normal." " Murmurs do not necessarily indicate the presence of heart disease." "There are no physical signs on which the diagnosis of angina pectoris can be made . . .. There may be no enlargement, no murmurs, no irregularity, nor any roentgenologic or electrocardiographic changes."

The illustrations are numerous and maintain the high standard of the text. In those showing a decimetre scale of height alongside the patient, it would be an advantage for the British reader if the exact height were given in millimetres or centimetres and inches.

The book, therefore, can be most highly recommended to the senior student of medicine and surgery, and to the postgraduate of all ages, and reflects the greatest credit on the authors and their school.

\section{CHRONIC DISEASES OF THE} ABDOMEN.

\section{A DIAGNOSTIC SYSTEM.}

By C. Jennings Marshall, M.S., M.D., F.R.C.S. Pages xvi+247. Chapman and Hall. Price 25/- net.

The object of this book is described by its subtitle. " Chronic Abdomen" is used in its widest sense and the book includes some consideration of diseases of and symptoms arising from contiguous organs and liable to lead to confusion in diagnosis, as well as descriptions of symptoms and signs arising from chronic abdominal disease and manifesting themselves away from their source of origin. The first part of the book (52 pages) deals with method of diagnosis and includes physical examination, special examinations and laboratory examinations. The second part deals with symptoms in turn, most of the first half being concerned with pain and the remainder with other cardinal symptoms in order.

The subject matter is carefully tabulated, cross references are freely used and the book is evidently intended to be a complete index of its subject. Your reviewer was therefore disappointed, when testing this completeness to find numerous omissions. In a few cases the index alone may be deficient though in a work of this nature this is itself a serious fault. Some of them were,-enteritis, regional enteritis (Crohne's Disease), coronary thrombosis, mesenteric thrombosis, dysentery (except for hepatic abscess), Richter's hernia, malrotation of the gut, hair-balls and phytobezoars, hiccough, periarteritis nodosa, acanthosis nigricans. The differential diagnosis of chronic intussusception is said to be carcinoma coli-abdominal tuberculosis, the more likely in children, is not mentioned in this connection nor is eventration of the diaphragm or thoracic stomach mentioned in the differential diagnosis of diaphragmatic hernia.

In spite of rather many omissions which prevent this book from being another "French" in its special field the student will find it packed with useful and accurate information arranged, for easy assimilation, in his favourite format. The printing, illustrations and diagrams are excellent.

\section{RHEUMATISM.}

By Bertram Nisse, M.D., M.R.C.P. Pp. 159. John Bale Medical Publications, Ltd. London. 1938. Price 5/-.

Here is another little book on rheumatism divided into rheumatic fever, fibrositis and arthritis. It gives the main facts which are known about these various conditions and is principally written for the general practitioner.

A good deal of space has been wisely devoted to treatment, and some attempt has been made to indicate the value of the various types of therapy.

There have been a great many small books of this sort published in the last few years and this book is at least as good as any of them. The importance of gout has been stressed and a chapter or so is devoted to 
irregular gout which may be read with profit.

The book will usefully serve the purpose for which it was written.

\section{WHITLA'S DICTIONARY OF TREATMENT.}

Including medical and surgical therapeutics, eighth edition.

By R. S. Allison, M.D., M.R.C.P., and C. A. Calvert, M.B., B.Ch., F.R.C.S.I. Baillière, Tindall \& Cox. London. 1938. Price 30/.

This well-known text-book originally written by the late Sir William Whitla, has now been re-written by members of the Belfast School of Medicine. It covers the whole field of medical and surgical treatment as in the original volume, and it is indeed a matter of some surprise and certainly congratulation that the field has been covered so adequately.

It is naturally impossible in considering a book which covers so wide a field to mention individual contributions, but the section dealing with chronic rheumatism and phthisis are particularly well written and comprehensive, and the section that deals with affections of the pituitary gland is also good. To show how thoroughly the book has been written, there is a paragraph in small type dealing with the gonadotropic hormone as also with the growth hormone, and mention is made of the effect of the pituitary on the thyroid through its thyrotropic principle. Mention is even made of the fact that hypophosectomy prevents diabetes mellitus in depancreatised dogs, a fact which was only discovered experimentally in 1931 and has only been applied to practical medicine very recently.

The authors have successfully carried their plan of action into effect but it seems doubtful in the present state of medicine whether it is wise to try and do so much in so little space. However, the book is only intended for reference where the relative values of various treatments are in doubt, and as this purpose is adequately fulfilled, it would be ungracious to elaborate the point, and of all the books on treatment-and they are many-this appears to be one of the very best.

\section{EVOLUTION OF OBSTETRIC ANALGESIA.}

By ANDrew M. Claye, M.D., F.R.C.S., F.C.O.G. Oxford Medical Publications. 1939. Price 6/-.

I have read, with great pleasure, Professor A. M. Claye's book on the " Evolution of Obstetric Analgesia." It is a small but excellent book in which Professor Claye deals briefly but very thoroughly with the subject.

I can recommend it strongly to all who are interested in the subject of analgesia in labour.

\section{CONTROL OF CONCEPTION.}

\section{(Second Edition.)}

By DR. R. L. Dickinson. Baillière, Tindall \& Cox. London. 1938. Price $16 \mathrm{~s}$.

Dr. Dickinson published his first text-book on this subject in joint authorship with Dr. Louise Bryant in 1931. Since then such a large amount of work has been done that a new edition became necessary, and this volume was issued in 1938.

Everyone who knows anything of contraception, honours Dr. Dickinson for his outstanding work in this field, he has given continuous attention to the subject from its earliest days and his prestige and professional standing have been of the greatest possible help to the birth control movement in America. The present publication is a textbook of 390 pages written strictly for medical practitioners and medical students and not for the general public. Its contents cover the anatomy, physiology and chemistry concerned in the subject, exhaustive descriptions of every known method of contraception, a useful chapter on methods of therapeutic abortion, details of equipment for birth control clinics, and a programme for future research.

The bibliography alone makes the book worth possessing. Eighteen pages of small type describe works in English, German and French. In each case the exact page references are given as well as names of publishers, journals and dates of publication. A feature of the book is the illustrations; there are 128 pages of fine drawings all executed by Dr. Dickinson himself. American text-books seem to be ahead of 